\title{
Use of a Tool to Determine Perceived Barriers to Children's Healthy Eating and Physical Activity and Relationships to Health Behaviors
}

\author{
Julie C. Jacobson Vann, PhD, MS, RN ${ }^{a,{ }^{*}}$, Joanne Finkle, JD ${ }^{b}$, Alice Ammerman, DrPh $^{c}$, \\ Steven Wegner, MD ${ }^{\mathrm{b}, \mathrm{d}}$, Asheley Cockrell Skinner, $\mathrm{PhD}^{\mathrm{b}}$, John T. Benjamin, $\mathbf{M D}^{\mathrm{b}}$, and Eliana \\ M. Perrin, MD \\ aUniversity of North Carolina at Chapel Hill, School of Nursing, Health Care Systems, Chapel Hill, \\ $\mathrm{NC}$ \\ bDivision of General Pediatrics and Adolescent Medicine, Department of Pediatrics, The \\ University of North Carolina at Chapel Hill, School of Medicine, Chapel Hill, NC \\ 'The University of North Carolina at Chapel Hill, Center for Health Promotion Disease Prevention, \\ Chapel Hill, NC \\ ${ }^{d}$ AccessCare, 3500 Gateway Centre Boulevard, Suite 130, Morrisville, NC
}

\section{Abstract}

This pilot investigation assesses whether barriers to children's healthy eating and physical activity reported by parents on a newly developed brief pediatric obesity screening and counseling tool are related to healthy eating and physical activity behaviors. The sample included parents of 115 Medicaid-enrolled children in a general pediatric clinic. Of 10 barriers, 7 were statistically associated with parent-reported behaviors with odds ratios (ORs) ranging from 0.6 to 9.4. Relationships remained significant when child characteristics were controlled in the analysis. Although additional testing is needed, the tool provides clinicians with an approach to identify barriers and behaviors for targeted counseling.

\section{Keywords}

Obesity; Healthy weight; Barriers; Behaviors; Nutrition; Physical activity

\begin{abstract}
United States' Youth are feeling the effects of an obesogenic society. An estimated $21.2 \%$ of 2 - to 5-year-olds and $35.5 \%$ of 6- to 11-year-olds are considered overweight or obese (Ogden, Carroll, Curtin, Lamb, \& Flegal, 2010). This is approximately double and triple, respectively, the prevalence observed 30 years ago in these age groups (Koplan, Liverman, Kraak, \& Committee on Prevention of Obesity in Children and Youth, 2005). For children, excess weight increases the risk for early-onset chronic health problems and potentially decreases social, psychological, and physical dimensions of quality of life (Schwimmer, Burwinkle, \& Varni, 2003; Williams, Wake, Hesketh, Maher, \& Waters, 2005). Overweight children are also at increased risk for becoming overweight or obese in adulthood, with a myriad of associated health problems (Baker, Olsen, \& Sorensen, 2007; Dietz, 1998). For society, the direct and indirect financial costs of childhood overweight and obesity add to the
\end{abstract}

(C) 2011 Elsevier Inc. All rights reserved.

*Corresponding author: Julie C. Jacobson Vann, PhD, MS, RN. jvann@ email.unc.edu (J.C. Jacobson Vann). 
already overwhelming economic burden stemming from adult overweight and obesity (Finkelstein, Trogdon, Cohen, \& Dietz, 2009; Powers, Rehrig, \& Jones, 2007).

Dietary behaviors, including consumption of sweetened beverages, excessive serving sizes, intake of fast food, and insufficient consumption of fruits and vegetables, have been associated with childhood overweight (Agras \& Mascola, 2005; Dubois, Farmer, Girard, \& Peterson, 2007; Kang et al., 2006; Lioret, Volatier, Lafay, Tourvier, \& Maire, 2009; Taveras et al., 2005). Increases in "screen time" and a decrease in physical activity behaviors are also related to excess weight gain in children (Andersen, Crespo, Bartlett, Cheskin, \& Pratt, 1998; Kang et al., 2006). Recently, these behaviors have often been attributed to a "toxic environment" that encourages larger portion sizes, sugar- and fat-laden foods, parents' long workdays, and less active lifestyles (Stettler, Signer, \& Suter, 2004; Sturm, 2005a, 2005b).

In published studies, parents have identified barriers to overcoming such a toxic environment when trying to feed their children healthy foods or help their children to be more physically active. Within the Health Belief Model, the concept of barriers has been defined as "one's opinion of the tangible and psychological costs of the advised action" (National Cancer Institute [NCI], 2005, p. 13). Several barriers to feeding children healthy food have been identified in published studies, including cost, preparation time, and children's food preferences (Ard et al., 2007; Hart, Herriot, Bishop, \& Truby, 2003; Kicklighter et al., 2007; Omar, Coleman, \& Hoerr, 2001). Cost and time have also been identified as barriers for parents trying to support children's increased physical activity (Gordon-Larsen et al., 2004; Irwin, He, Bouck, Tucker, \& Pollett, 2005; McGarvey et al., 2006). Other barriers to physical activity include neighborhood safety concerns and children's own fears related to bullies on playgrounds (Gable, Chang, \& Krull, 2007; Gordon-Larsen et al., 2004; McGarvey et al., 2006; Weir, Etelson, \& Brand, 2006).

Pediatric nurses and primary care providers are well positioned to identify and intervene with children who are at risk for or are already overweight to increase healthful eating and physical activity behaviors. However, in today's fast-paced health services environment, it can be challenging for care providers to allocate their limited time to competing demands. Even when a clinician's intent to perform a behavior is high, obstacles may interfere with carrying out the behavior (Perkins et al., 2007). Good clinician intentions can be supported with systems that are likely to facilitate performance improvement. For example, toolkits may be useful for improving provider involvement in counseling patients on health behaviors if the tools address barriers to implementation of intended actions (Perkins et al., 2007). The North Carolina Medicaid program sought to provide clinicians in the program with simple and effective time-saving tools that would combine and match screening questions with counseling tips for parents. The tools were intended to assist clinicians with assessing children's health behaviors and providing parents with targeted health education related to preventing and treating overweight and obesity. A healthy eating and physical activity screening and counseling tool was developed as a component of the healthy weight toolkit. Development of this tool is described below. The objective of this secondary data analysis of a prior intervention was to conduct preliminary testing of the newly developed rapid assessment and counseling tool. The testing involved assessing whether the barriers to healthy eating and physical activity are associated with behaviors that reflect known risks of childhood overweight and obesity. Barriers that are shown to be associated with physical activity and nutrition health behaviors may be important for clinicians to address with families in promoting healthy behaviors or for communities to intervene at the population level. 


\section{Theoretical Framework}

The web of causation, Health Belief Model, Rogers' diffusion of innovations model, and transtheoretical model guided the development of the healthy eating and physical activity screening and counseling tool (Adams, 2009; Centers for Disease Control and Prevention [CDC], 2007; Clement, 2008; De Civita \& Dasgupta, 2007; Duncan, 2007; Fahey \& Burbridge, 2008; Mausner \& Bahn, 1974, chap. 2; NCI, 2005; Stanhope, \& Lancaster 1996, chap. 13; Wofford, 2008). This tool is called Starting the Conversation (STC). The web of causation, originally conceived by MacMahon et al., essentially proposes that diseases or effects develop as the result of multiple factors or causes, each of which also results from "a complex genealogy of antecedents" (Duncan, 2007; Mausner \& Bahn, 1974, chap. 2). The large number of antecedents creates the web. Individual-, family-, and community-level factors are important to the development of obesity (Wofford, 2008). This model, combined with review of evidence from the literature and obesity experts, has guided the selection of items for tool. The barriers in the tool are expected to be antecedents to eating and physical activity behaviors.

The Health Belief Model focuses on health behavior changes and incorporates four original and two newer constructs: perceived susceptibility, perceived severity, perceived benefits, perceived barriers, cues to action, and self-efficacy (NCI, 2005). The screening and counseling tool was designed, in part, to identify perceived barriers that may prevent people from taking positive action to changing health behaviors (NCI, 2005). This is an important first step in helping families develop plans of action that reduce the adverse effects of barriers. The STC was designed with "tips" for helping children eat well and be physically active. These tips function as cues to action, providing parents with strategies to improve their children's health behaviors and remind them of negotiated plans for behavior changes (NCI, 2005).

Rogers' diffusion of innovation model suggests that the adoption of an innovation involves the interaction of the individuals adopting the innovation (the clinicians) and the innovation itself, the STC (De Civita \& Dasgupta, 2007). Within this model, the rate of adoption of the innovation is dependent on the characteristics of the innovation, the methods used to communicate, the characteristics of the users, and the social systems in which the innovation is introduced (Adams, 2009). The STC was designed to address the concepts in the model of relative advantage, compatibility, and complexity (Fahey \& Burbridge, 2008) by creating a tool that can be efficiently applied in a fast-paced environment, combining screening with counseling strategies, and breaking down the components into manageable parts. The characteristics of the tool are intended to facilitate adoption of the STC tool by clinicians.

The transtheoretical model specifies the stages of change or degree of readiness to change or begin new behaviors (Clement, 2008). The stages in the model include precontemplation, contemplation, preparation, action, and maintenance (CDC, 2007; Henry, 2005). The STC also included nutrition and physical activity readiness to change questions to assist clinicians with identifying the parents' receptiveness to helping their children improve health behavior and intervene based on readiness.

\section{Methods}

\section{Study Design and Participants}

Pediatric patients and their parents were recruited between April 2005 and March 2006 at the University of North Carolina at Chapel Hill (UNC-CH), Child and Adolescent General Clinic for an exploratory correlational (Brink \& Wood, 1997) pilot study of a brief intervention aimed at preventing and treating childhood obesity in a primary care setting. 
Parents and their children were eligible to participate if the children were 4 to 12 years of age, seen in the clinic for a well-child visit or minor illness, and insured by North Carolina Medicaid or the State Children's Health Insurance Program (SCHIP). The study was restricted to English-speaking parents because this was a pilot study and the tool of interest had not yet been translated for families speaking other languages. This study was approved by the UNC-CH School of Medicine Institutional Review Board (Protocol 04-HPDP-771).

\section{Study Procedures}

Clinic appointment schedules were reviewed to identify potentially eligible children. All potentially eligible parents and children were approached in private examination rooms by a research associate. Study objectives and procedures were explained to families; informed consent was obtained from parents. Assent was obtained from children at least 7 years of age. Parents were asked to complete the two-page STC tool (described under Study Instruments and Measurement) and a brief intake tool consisting of contact and demographic information.

\section{Study Instruments and Measurement}

The Starting the Conversation Nutrition and Physical Activity tool for 4- to 12-year-olds (STC-4-12) is a two-part, evidence-informed rapid assessment tool and tailored counseling guide designed for use by nurses and other primary care providers (Perrin, Finkle, \& Benjamin, 2007). The STC-4-12 tool was designed with the goal of facilitating efficient, consistent, and structured yet individualized assessment and counseling by clinicians in a fast-paced environment. The Nutrition STC-4-12 includes five "barrier" questions, five nutrition behavior questions, a parental "readiness to change" question, and two to three "tips to help your child eat well" for each behavior and barriers nutrition question. Barrier questions were intended to measure beliefs and behaviors that may inhibit parents from helping their children engage in behaviors that are likely to help promote healthy weight. The Physical Activity STC-4-12 consists of five physical activity "barriers" questions, five physical activity behaviors questions, one parental readiness to change question, and two to three "tips to help your child be more active" for each physical activity question. The tips for helping children eat well and be more active are matched with each behavior and barrier question to guide counseling by clinicians and serve as take-home reminders for parents. All except one of the STC-4-12 barriers and behaviors questions included response scales with three choices. The question asking about type of milk consumed most often added a fourth response option: "none." The STC-4-12 questions and response options are listed in Appendix 1.

The STC-4-12 tool was developed through a yearlong iterative qualitative consensus process by a team of nurses, pediatricians, nutritionists, and epidemiologists with expertise in childhood obesity. Prior to developing the STC-4-12, currently available nutrition and physical activity education, assessment, and counseling tools developed for clinician use were obtained from Internet searches, clinical practices throughout North Carolina, and outof-state clinics known for obesity assessment and counseling measures. Focus groups were held with clinicians at six primary care practices to explore experiences with existing obesity screening and counseling tools, perceived strengths and weaknesses of each tool, and attributes of tools that would be helpful for them to assess and counsel overweight and obese patients. Focus group responses were summarized qualitatively by theme. Results of focus groups were published previously (Flower, Perrin, Viadro, \& Ammerman, 2007). Extensive literature searches were conducted on factors associated with healthy eating, physical activity, and childhood overweight and obesity. Identified instruments, evidence of instrument effectiveness, relevant literature, and focus group responses were reviewed and qualitatively analyzed by the development team. It was determined that few existing tools 
were culturally sensitive for minority and low-income populations and of the appropriate literacy level for Medicaid populations or fostered interactive exchange between the patient, parent, and provider. In addition, many tools did not appear to be based on evidence or theory.

The format of STC-4-12 was based on previously developed STC tools for adults (STCadult) that focused on healthy eating and physical activity (NC Prevention Partners, 2010; Gaskins et al., 2007; Glasgow et al., 2005). Approximately 60\% of the STC-4-12 questions were obtained from the adult healthy eating and physical activity STCs, with questions modified for children as necessary. The STC-adult development involved extensive formative and pilot testing. The adult dietary STC was validated using comparisons to the longer validated 54-item Dietary Risk Assessment (DRA) Scores and serum carotenoid levels (Paxton, Ammerman, Gizlice, Johnston, \& Keyserling, 2007). The DRA score and total STC score were highly correlated $(r=.67, p<.0001)$. The STC-4-12 was pretested with parents and clinicians at two primary care clinics during a 3-week period by a nutritionist and nurse investigator. Feedback from clinicians and parents was used to modify and increase the clarity of questions and response options. Internal consistency of the STC-4-12 was assessed through computation of Cronbach's alpha with an overall scale reliability coefficient of .75, calculated using all items in their original scales (Carmines \& Zeller, 1979, chap. 4).

\section{Data Management and Analysis}

Teleform software was used to facilitate data collection and entry and export of the parent survey and intake tool. The STC forms were printed as three-part carbonless forms. These data were manually entered into a database. Statistical analyses were conducted using Stata 10 (College Park, TX) and SAS 9.1.3 (Cary, NC).

\section{Statistical Analysis}

The gamma statistic was used to assess the strength and direction of relationships between pairs of STC barrier and behavior measures, with statistical significance determined by $95 \%$ confidence intervals (CIs). The gamma statistic or coefficient is a correlation measure, equivalent to Spearman's $R$ or Kendall tau. This measure is appropriate for ordinal categorical data and is preferable when the data contain many tied observations. Gamma takes values between -1 and 1 . A gamma value less than zero indicates a negative association; a gamma value greater than zero indicates a positive association; and a gamma value of zero means that the measures are independent (Stevens et al., 2004).

The potential influence of demographic characteristics on relationships between barriers and behaviors was assessed using logistic regression. For ease of interpretation, some of the response categories for dependent (behavior) and explanatory (barrier) variables were combined to create two response categories instead of three. For example, the barriers response categories agreeing "a little" and "a lot" were combined to compare to those who disagreed at all with barrier statements. Unadjusted ORs were computed to represent the effect of agreeing "a little" or "a lot" to a barrier on each behavior. Adjusted ORs (aORs) and CIs were computed using the results of logistic regression to assess the relationships between barriers and behaviors while controlling for age, gender, race, and ethnicity of the children. ORs can be used to describe the strength of associations. An OR of 1.0 indicates no observed statistical association between the barrier and behavior. An OR greater than 1.0 indicates a positive relationship, and an OR less than 1.0 indicates a negative relationship. The OR is difficult to interpret directly. However, because the OR is often considered an estimate of the relative risk, it is easiest to interpret the OR as a relative risk or risk ratio for simplicity. A simplistic interpretation of an OR of 9.4 in this study is as follows: parents 
who agree that their children do not like healthy foods are 9.4 times more likely to report that their children eat two or fewer servings of fruits and vegetables compared with parents who disagree with the statement. A CI for an OR that does not include 1.0 is considered a statistically significant result. Because the variables are somewhat dependent on one another, a Bonferroni's correction was not applied, as the corrections would be expected to be highly conservative and miss real associations, increasing type II errors (Garamszegi, 2006).

\section{Results}

\section{Study Sample and Patient and Parent Characteristics}

The mean age of participating children was 7.5 years at enrollment (Table 1). Of the 115 enrolled children, approximately half were female. Most children were non-Hispanic (92\%), self-identified as Black or African American (66\%), and insured by Medicaid (82.6\%). The children and their parents primarily lived in urban areas, based on Rural-Urban Commuting Area codes (Hart, Larson, \& Lishner, 2005). More than one third of the children (34.8\%) were obese (body mass index [BMI] 295 th percentile), and $14.8 \%$ were overweight (BMI $\geq$ 85\%; Barlow \& Expert Committee, 2007). Most (92.2\%) of the responding parents were female, and more than one half (54.8\%) of the parents considered themselves to be overweight (Table 1).

\section{Barriers to Healthy Eating}

Approximately half of the parents agreed "a little" or "a lot" to the statements "My child likes to eat in front of the TV or at the computer" and "Healthy foods cost too much" (Table 2). In addition, $36.5 \%$ of the parents agreed "a little" or "a lot" with the statement "My child doesn't like healthy foods."

\section{Barriers to Physical Activity}

More than one half of the parents agreed "a little" or "a lot" to the statements "When my child misbehaves, I take away their outdoor/indoor play time" (55.7\%) and "It's hard for me to find time to play outside with my child" (50.4\%; Table 2). In addition, more than $40 \%$ of parents agreed with the statement "It takes too much time and money to have my child involved with sports programs."

\section{Relationships Between Barriers to Healthy Eating and Nutrition-Related Behaviors}

Three of five queried dietary barriers were found to be significantly associated with at least one healthy eating behavior, based on a modest to strong gamma statistic. The parental belief that "Sometimes it seems like the only way to get my child to behave is to promise candy or other food treats" was associated with reports that children ate fewer servings of fruits and vegetables $(\gamma=0.50,95 \% \mathrm{CI}=0.18-0.82)$ and ate food purchased away from home more often $(\gamma=0.33,95 \% \mathrm{CI}=0.16-0.65)$. The parental perception that "My child doesn't like healthy foods" was strongly associated with children eating less servings of fruits and vegetables $(\gamma=0.75,95 \% \mathrm{CI}=0.58-0.92)$ and moderately associated with eating a greater number of junk food snacks $(\gamma=0.43,95 \% \mathrm{CI}=0.18,0.68)$. Logistic regression modeling supported the significant gamma correlation results (Figure 1) and demonstrated that significant associations observed between healthy eating barriers and behaviors remained generally consistent after adjusting for patient characteristics. The strongest association was observed between the barrier "My child doesn't like healthy foods" and lower reported fruit and vegetable consumption $(\mathrm{aOR}=9.4,95 \% \mathrm{CI}=3.5-24.9)$. Parental agreement with the statement "Sometimes it seems like the only way to get my child to 
behave is to promise candy or other food treats" was significantly related to three of four tested behaviors, with adjusted ORs ranging from 3.1 to 7.6 (Figure 1).

\section{Relationships Between Barriers to Physical Activity and Physical Activity-Related Behaviors}

Four of five queried barriers to physical activity were significantly associated with at least one physical activity-related behavior. Parents who reported that "It's hard for me to find time to play outside with my child" were more likely to report fewer "hours of active play" by children $(\gamma=0.57,95 \% \mathrm{CI}=0.35-0.79)$, fewer days in which the "family or community do active things together" $(\gamma=0.44,95 \% \mathrm{CI}=0.20-0.68)$, more hours of child's "screen time" $(\gamma=0.39,95 \% \mathrm{CI}=0.17-0.62)$, fewer days playing outdoors $(\gamma=0.39,95 \% \mathrm{CI}=$ $0.15-0.63)$, and less frequent child involvement in "school sports teams or community groups" $(\gamma=0.33,95 \% \mathrm{CI}=0.06-0.59)$ than parents who disagreed with the barrier statement about finding time to play with their children. The belief that "My child feels s/he will get teased when playing outside or on a team" was associated with fewer days of playing outdoors per week $(\gamma=0.49,95 \% \mathrm{CI}=0.11-0.86)$ and fewer days per week in which the "family or community do active things together" $(\gamma=0.40,95 \% \mathrm{CI}=0.14-0.68)$. The concern that "It takes too much time and money to have my child involved with sports programs" was related to less frequent participation in active family or community events $(\gamma$ $=0.41,95 \% \mathrm{CI}=0.14-0.68)$. Findings from logistic regression modeling support the significant correlation analyses $(\gamma)$ for the proposed barriers: "It's hard for me to find time to play outside with my child"; "It takes too much time and money to have my child involved with sports programs"; and "When my child misbehaves, I take away their outdoor/indoor play time." Parental agreement with the statement "It's hard for me to find time to play outside with my child" was associated with reports of lower levels of activity for all five physical activity behaviors, with adjusted ORs ranging from 2.2 to 5.5 (Figure 2).

\section{Discussion}

In this study, statistically significant relationships were observed between 7 of 10 proposed barriers to healthy eating and physical activity and one or more health behaviors included in the brief STC-4-12 screening and counseling tool. Observed statistical relationships were particularly strong for the barriers that children do not like healthy foods and parents have difficulty finding time to play outside with their children. Parents who reported that their children did not like healthy foods were more likely to report that their children consumed fewer servings of fruits and vegetables and ate two or more unhealthy snacks per day. Parents who agreed with the statement that it is "hard to find time to play outside with my child" were more likely to report that their children had fewer hours of active play, more screen time, rare or no involvement in sports or community groups, and infrequent participation in active community or family events. Other perceived barriers that show significant statistical relationships with unhealthy behaviors include parents' beliefs that they need to promise food treats to get children to behave, parents' beliefs that their children like to eat in front of the television or computer, parental practice of taking away play time if children misbehave, and concerns that it takes too much time and money for sports programs.

In this study, the significant relationship observed between parents' perceptions that their children do not like healthy foods and reports of children consuming fewer servings of fruits and vegetables is supported by published results of surveys and focus groups. In one survey of 4,746 adolescents in Minnesota, one of the strongest correlates of fruit and vegetable consumption was taste preferences (Neumark-Sztainer, Wall, Perry, \& Story, 2003). However, the relationship between fruit and vegetable intake and taste preferences was modified by the availability of fruits and vegetables (Neumark-Sztainer et al., 2003). Even 
when fruit and vegetable taste preferences were reported to be low, self-reported intake increased, on average, when fruits and vegetables were made available (Neumark-Sztainer et al., 2003), for example, through having them in view of the adolescent (Story, NeumarkSztainer, \& French, 2002). A focus group-based study of 213 children with ages 7 to 17 years also ranked internal/physiologic preferences such as taste preferences and cravings to be a barrier to healthful eating (O'Dea, 2003). Similar relationships were identified in a published review of the literature (Jenkins \& Horner, 2005) and other studies of children and adolescents (Hart et al., 2003; Kicklighter et al., 2007; Neumark-Sztainer, Story, Perry, \& Casey, 1999).

In this study, $41.7 \%$ of parents agreed "a little" or "a lot" to the statement "Healthy foods cost too much." However, this perceived barrier to healthy eating was not associated significantly with eating behaviors included in the STC-4-12. This finding was unexpected because cost has been identified as a barrier to healthy eating in other published studies. In a study of households of 1,355 children in Alabama, higher costs of fruits and vegetables, as measured by the Agricultural Research Service of the United States Department of Agriculture, was inversely related to availability in the homes (Ard et al., 2007). Other studies employing focus groups of parents or grandparents caring for children cited cost as a barrier to healthy eating (Hart et al., 2003; Kicklighter et al., 2007; Omar et al., 2001; Story et al., 2002); yet, one study reported that parents may have had misperceptions about what are considered to be healthy foods (Hart et al., 2003). It is possible that the lack of statistical association between perceived cost and healthy eating in this study is related to parental misperceptions about healthy foods or that parents may strive to overcome perceived barriers such as cost.

The general lack of statistical association in this study between the perception that healthy foods take too long to prepare and healthy eating behaviors was unexpected and inconsistent with studies that examined time as a potential barrier to healthy eating. In a study of male and female caregivers of young children in three rural counties in Michigan, scarcity of time was specified as one of three major barriers to providing healthy meals (Omar et al., 2001). Caregivers cited demands of outside work, as well as time to plan, shop, and prepare healthy meals (Omar et al., 2001). In this study, most parents (88.7\%) disagreed with the statement that healthy meals take too long to prepare. One possible explanation for the small proportion of participants who reported that healthy meals take too long to prepare may be the focus on healthy food preparation in the media through, for example, cooking programs. The relative lack of variability in the responses to this barriers question may help to explain the absence of a statistically significant association between time as a barrier and any of the healthy eating behavior questions.

Time and/or money are perceived as barriers to children's physical activity in published scientific literature (Gordon-Larsen et al., 2004; Irwin et al., 2005; McGarvey et al., 2006) and in this study. Approximately half (50.4\%) of parents in this study reported that it is hard to find time to play outside with their children, and $41.4 \%$ indicated that it takes too much time and money to have children involved in sports programs. These time and money barriers in the STC-4-12 were significantly statistically associated with physical activity behaviors, most consistently for the former time barrier. In a North Carolina church-based pilot project of African American girls, with ages 6 to 9 years, and their female caregivers, perceived environmental barriers, such as lack of affordable and accessible recreational resources, were believed to reduce opportunities for physical activity (Gordon-Larsen et al., 2004). In a Canadian study of parents of preschool children, time and finances were two of nine barriers and facilitators of adequate physical activity (Irwin et al., 2005). 
The findings from this pilot study suggest that several parental beliefs and other potential barriers to healthy eating and physical activity play essential roles in the multifactorial web of causation related to the development of childhood overweight and obesity. A parent's belief related to healthy food or physical activity, regardless of whether the belief matches reality, can either encourage or discourage healthy behaviors. When a belief discourages a healthy behavior, the belief becomes an internal barrier. Examples of internal barriers include beliefs such as using food as a reward for good behavior will result in a more obedient child, preparing healthy foods takes too much time, or being physically active costs too much. The perception that a neighborhood is unsafe for outdoor play can also be an internal barrier when the fear is not based in reality (Weir et al., 2006). Although some healthy foods are expensive, a parent's belief that all healthy foods are too expensive may keep the parent from making dietary improvements. Family beliefs are important for health care providers to consider when working with families on healthy lifestyle changes.

Additional studies are needed to more clearly elucidate the relationships between perceived barriers to healthy eating and physical activity, health behaviors, and weight status of children. The results of this study add to a growing body of research that seeks to further understand barriers to healthy weight and identify, develop, and/or evaluate lifestyle interventions aimed at preventing and reducing childhood overweight and obesity (American Academy of Pediatrics [AAP], 2003; Nemet et al., 2005; Wilfley et al., 2007). The potential value of the STC-4-12 in promoting healthy weight in children can be strengthened with further research and testing of the tool. The STC-4-12 should be tested with a larger sample to continue to assess relationships between barriers and behaviors and to determine whether these relationships vary based on children's age. Additional testing of the STC-4-12 should include comparisons of the relationships between barriers and behaviors for children who are overweight as compared with those who are not overweight. Longitudinal studies should be conducted to assess the potential effectiveness of clinician's use of the STC-4-12 tool with helping families improve targeted health behaviors and weight status of children. Until additional testing is completed, this tool may be valuable for clinicians to use to help initiate conversations with patients and families about health behaviors and barriers.

\section{Limitations}

There are several important limitations to this study. First, the study sample was selected from only one clinic and was limited to those who spoke English and were enrolled in the State Medicaid or SCHIP, raising questions of generalizability. For example, the item "Healthy foods cost too much" is likely to be less relevant to families of higher socioeconomic status. Yet, generally, the behaviors and barriers constructs were identified from literature and clinician experiences that included families of varying socioeconomic backgrounds. Testing this screening and counseling tool in other populations, including those with private health insurance, is an important next step. In addition, modified versions of the tool will need to be developed and tested for families with culturally diverse backgrounds that may influence health behaviors and weight status through unique pathways.

A second limitation of the study is the small sample size and large CIs. A larger sample size may have increased the precision and therefore narrowed the CIs for study measures and increased the number of observed positive relationships that were found to be statistically significant. To maximize the sample size and minimize the CIs for study measures, all potentially eligible parents and their children were asked to participate. In addition, parents rarely refused to participate. The small sample size may be attributed to the relatively infrequent occurrence of parents scheduling and bringing their 4- to 12-year-olds to clinic 
for well-child visits in this population. It is also possible that the responses of parents who take their 4- to 12-year-old children to well-child visits may differ from those who do not routinely take their child to well-child visits.

A third limitation to be considered when interpreting results is that this is a small preliminary pilot project using an instrument that has not been fully statistically tested for reliability and validity, especially for the $40 \%$ of the items that were not directly taken from the adult STC. Internal consistency of the items in the STC-4-12 was tested through computation of Cronbach's alpha. Face validity was assessed by nurses, physicians, and nutritionists who have extensive experience with childhood obesity. Pretesting was performed with both parents and primary care clinicians. Focus groups and published literature were used to identify and verify salient barriers and behaviors for rapid screening, supporting content validity. Criterion-related validity was tested, in part, through statistically assessing the relationships between the barriers and behaviors (Carmines \& Zeller, 1979, chap. 2). However, additional testing of the STC-4-12 is needed.

The list of barriers in the STC-4-12 was derived from preliminary exploratory work through an iterative process involving a team of pediatric health care professionals working with community and clinic populations. Because this tool was developed to assist clinicians with rapid assessment when time is significantly limited, the screening and counseling tool did not include a comprehensive compilation of barriers. Although the intent was to include only a limited number of items when designing the tool, it is possible that other barriers more strongly associated with eating and physical activity may have been omitted. Ongoing efforts should be made to identify critical potential barriers to healthy eating and physical activity.

In addition, there is a potential for response bias, as parents may be more likely to underreport both barriers and children's unhealthy behaviors to their children's health care providers. If parental underreporting of barriers is systematically different than underreporting of unhealthy behaviors, then the observed associations between barriers and behaviors are likely to be biased. In addition, it was not determined if the magnitude of the reported barriers were related to specific health behaviors. Finally, it was not determined whether parents who perceived specific barriers had worked to overcome some of the barriers.

\section{Conclusions}

This exploratory pilot study suggests that many of the proposed barriers to healthy eating and physical activity questions included in the study instrument were strongly associated with parental reports of their children's behaviors. Several of the identified associations were supported by previously published literature concerning barriers to healthy eating and physical activity. Additional research is needed to assess whether the STC-4-12 screening and counseling tool is helpful for families in their efforts to improve health behaviors and prevent or reverse any resultant unhealthy weight trajectories. Recognizing the need for further testing, clinicians may find the tool useful for beginning the conversations with parents and children about reducing barriers and increasing healthy behaviors.

\section{Acknowledgments}

This project was supported by Dr. Perrin's NIH K23 career development award (1K23 HD051817-01A1), Dr. Ammerman's R01 (5 R01 HD050981-02), and Dr. Skinner's Postdoctoral Fellowship (5 T32 NR008856).

The authors would like to thank Lung-Chang Chien for his assistance with graphics, Moonsu Kang for assistance with data analysis, Kori Flower, MD, MPH and Sari Teplin, MS, MPH for their contributions to original tool 
development, and Karah Daniels, MA, Gina Chung, EdM, and Lisa Pullen-Davis, PhD, MSPH for project planning and implementation support.

\section{Appendix 1}

Starting the Conversation Nutrition and Physical Activity, Barriers, and Behaviors Questions, Ages 4-12

\begin{tabular}{|c|c|}
\hline Question & Response Options \\
\hline \multicolumn{2}{|l|}{ Healthy eating behaviors } \\
\hline $\begin{array}{l}\text { How many servings of fruits and/or vegetables does your child } \\
\text { eat each day? }\end{array}$ & 5 or more, $3-4$, less than 3 \\
\hline $\begin{array}{l}\text { How many sugary drinks (soda, sports drinks, sweet tea, } \\
\text { lemonade, "Kool-Aid") and fruit juice does your child drink each } \\
\text { day? }\end{array}$ & 1 or fewer, 2 , more than 2 \\
\hline $\begin{array}{l}\text { How many snacks like cakes, cookies, ice cream, candy, and } \\
\text { chips does your child eat each day? }\end{array}$ & 1 or fewer, $2-3$, more than 3 \\
\hline $\begin{array}{l}\text { How many times a week does your child eat food purchased } \\
\text { away from home (fast food, convenience stores, vending } \\
\text { machines)? }\end{array}$ & 1 or fewer, $2-3$, more than 3 \\
\hline The milk that my child most often drinks is... & Skim or $1 \%$ milk, $2 \%$, whole, none \\
\hline \multicolumn{2}{|l|}{ Healthy eating barriers } \\
\hline $\begin{array}{l}\text { Sometimes it seems like the only way to get my child to behave } \\
\text { is to promise candy or other food treats. }\end{array}$ & Disagree, agree a little, agree a lot \\
\hline "Healthy foods cost too much." & Disagree, agree a little, agree a lot \\
\hline "My child doesn't like healthy foods." & Disagree, agree a little, agree a lot \\
\hline "I find that healthy meals take too long to prepare." & Disagree, agree a little, agree a lot \\
\hline "My child likes to eat in front of the TV or at the computer." & Disagree, agree a little, agree a lot \\
\hline \multicolumn{2}{|l|}{ Readiness to change (nutrition) } \\
\hline \multirow[t]{4}{*}{$\begin{array}{l}\text { How do you feel about making some changes to help your child } \\
\text { eat healthier? }\end{array}$} & I am not interested in making changes at this time. \\
\hline & $\begin{array}{l}\text { I am not ready to make changes yet, but want to } \\
\text { talk more. }\end{array}$ \\
\hline & $\begin{array}{l}\text { I am ready to make some changes now and would } \\
\text { like help. }\end{array}$ \\
\hline & $\begin{array}{l}\text { I am already helping my child to eat healthier and } \\
\text { don't feel there is much more to do. }\end{array}$ \\
\hline \multicolumn{2}{|l|}{ Physical activity behaviors } \\
\hline How many hours of active play does your child get every day? & More than 2,1-2, fewer than 1 \\
\hline How many days a week does your child play outdoors? & 5 or more, $3-4,0-2$ \\
\hline $\begin{array}{l}\text { How many hours of "screen time" (TV, video, computer games) } \\
\text { does your child get each day? }\end{array}$ & $0-2,3$, more than 3 \\
\hline $\begin{array}{l}\text { How often is your child involved in school sports teams or } \\
\text { community groups like basketball, swimming or step/dance? }\end{array}$ & More than once a week, once a week, rarely/never \\
\hline $\begin{array}{l}\text { How many days a week does your family or community do } \\
\text { active things together? }\end{array}$ & More than 3, 2-3, less than 2 \\
\hline \multicolumn{2}{|l|}{ Physical activity barriers } \\
\hline $\begin{array}{l}\text { "When my child misbehaves, I take away their outdoor/indoor } \\
\text { play time." }\end{array}$ & Disagree, agree a little, agree a lot \\
\hline "It's hard for me to find time to play outside with my child." & Disagree, agree a little, agree a lot \\
\hline $\begin{array}{l}\text { "It takes too much time and money to have my child involved } \\
\text { with sports programs." }\end{array}$ & Disagree, agree a little, agree a lot \\
\hline
\end{tabular}




\begin{tabular}{|c|c|}
\hline Question & Response Options \\
\hline $\begin{array}{l}\text { "My child feels that s/he will get teased when playing outside or } \\
\text { on a team." }\end{array}$ & Disagree, agree a little, agree a lot \\
\hline $\begin{array}{l}\text { "I feel like I'm too busy to drive my child to activities and } \\
\text { sports." }\end{array}$ & Disagree, agree a little, agree a lot \\
\hline \multicolumn{2}{|l|}{ Readiness to change physical activity } \\
\hline \multirow{4}{*}{$\begin{array}{l}\text { How do you feel about making some changes to help your child } \\
\text { be more active? }\end{array}$} & I am not interested in making changes at this time. \\
\hline & $\begin{array}{l}\text { I am not ready to make changes yet, but want to } \\
\text { talk more. }\end{array}$ \\
\hline & $\begin{array}{l}\text { I am ready to make some changes now and would } \\
\text { like help. }\end{array}$ \\
\hline & $\begin{array}{l}\text { I am already helping my child to be more active } \\
\text { and don't feel there is much more to do. }\end{array}$ \\
\hline
\end{tabular}

\section{References}

Adams S. Use of evidence-based practice in school nursing: Survey of school nurses at a national conference. The Journal of School Nursing. 2009; 25:302-313. [PubMed: 19363108]

Agras WS, Mascola AJ. Risk factors for childhood overweight. Current Opinions in Pediatrics. 2005; 7:648-652.

American Academy of Pediatrics. Committee on Nutrition. Policy statement: Prevention of pediatric overweight and obesity. Pediatrics. 2003; 112:424-430. [PubMed: 12897303]

Andersen RE, Crespo CJ, Bartlett SJ, Cheskin LJ, Pratt M. Relationship of physical activity and television watching with body weight and level of fatness among children: Results from the third national health and nutrition examination survey. Journal of the American Medical Association. 1998; 279:938-942. [PubMed: 9544768]

Ard JD, Fitzpatrick S, Desmond RA, Sutton BS, Pisu M, Allison DB, et al. The impact of cost on the availability of fruits and vegetables in the homes of schoolchildren in Birmingham, Alabama. American Journal of Public Health. 2007; 97:367-372. [PubMed: 17138914]

Baker JL, Olsen LW, Sorensen TI. Childhood body-mass index and the risk of coronary heart disease in adulthood. New England Journal of Medicine. 2007; 357:2329-2337. [PubMed: 18057335]

Barlow SE. Expert Committee. Expert committee recommendations regarding the prevention, assessment, and treatment of child and adolescent overweight and obesity: Summary report. Pediatrics. 2007; 120(Suppl 4):S164-S192. [PubMed: 18055651]

Brink, PJ.; Wood, MJ. Advanced design in nursing research. Thousand Oaks, CA: Sage Publications; 1997.

Carmines, EG.; Zeller, RA. Reliability and validity assessment. Newbury Park: Sage Publications; 1979.

Centers for Disease Control and Prevention. [Retrieved July 1, 2009] Program operations guidelines for STD Prevention, community and individual behavior change interventions. 2007. from: http://www.cdc.gov/std/Program/community/9-PGcommunity.htm\#diffusion.

Clement D. The transtheoretical model: An exploratory look at its applicability to injury rehabilitation. Journal of Sports Rehabilitation. 2008; 17:269-282.

De Civita M, Dasgupta K. Using diffusion of innovations theory to guide diabetes management program development: An illustrative example. Journal of Public Health. 2007; 29:263-268. [PubMed: 17562720]

Dietz WH. Health consequences of obesity in youth: Childhood predictors of adult disease. Pediatrics. 1998; 101(3 Pt 2):518-525. [PubMed: 12224658]

Dubois L, Farmer A, Girard M, Peterson K. Regular sugar-sweetened beverage consumption between meals increases risk of overweight among preschool-aged children. Journal of American Dietetic Association. 2007; 107:924-934. 
Duncan, DF. [Retrieved January 30, 2010] Epidemiology: Basis for disease prevention and health promotion. Multicausality and webs of causation. 2007. from: http://duncansepidemiology.tripod.com/id9.html.

Fahey DF, Burbridge G. Application of diffusion of innovations models in hospital knowledge management systems: Lessons to be learned in complex organizations. Hospital Topics. 2008; 86:21-31. [PubMed: 18450559]

Finkelstein EA, Trogdon JG, Cohen JW, Dietz W. Annual medical spending attributable to obesity: Payer- and service-specific estimates. Health Affairs. 2009; 28:w822-w831. [PubMed: 19635784]

Flower KB, Perrin EM, Viadro CI, Ammerman AS. Using body mass index to identify overweight children: Barriers and facilitators in primary care. Ambulatory Pediatrics. 2007 ; 7:38-44. [PubMed: 17261481]

Gable S, Chang Y, Krull JL. Television watching and frequency of family meals are predictive of overweight onset and persistence in a national sample of school-aged children. Journal of American Dietetics Association. 2007; 107:53-61.

Garamszegi LZ. Comparing effect sizes across variables: Generalization without the need for Bonferroni correction. Behavioral Ecology. 2006; 17:682-687.

Gaskins ND, Sloane PD, Mitchell CM, Ammerman A, Ickes SB, Williams CS. Poor nutritional habits: A modifiable predecessor of chronic illness? A North Carolina Family Medicine Research Network (NC-FM-RN) study. Journal of the American Board of Family Medicine. 2007; 20:124134. [PubMed: 17341748]

Glasgow RE, Ory MG, Klesges LM, Cifuentes M, Fernald DH, Green LA. Practical and relevant selfreport measures of patient health behaviors for primary care research. Annals of Family Medicine. 2005; 3:73-81. [PubMed: 15671195]

Gordon-Larsen P, Griffiths P, Bentley ME, Ward DS, Kelsey K, Shields K, et al. Barriers to physical activity: Qualitative data on caregiver-daughter perceptions and practices. American Journal of Preventive Medicine. 2004; 27:218-223. [PubMed: 15450634]

Hart KH, Herriot A, Bishop JA, Truby H. Promoting healthy diet and exercise patterns amongst primary school children: A qualitative investigation of parental perspectives. Journal of Human Nutrition and Dietetics. 2003; 16:89-96. [PubMed: 12662367]

Hart LG, Larson EH, Lishner DM. Rural definitions for health policy and research. American Journal of Public Health. 2005; 95:1149-1155. [PubMed: 15983270]

Henry DA. Nurse practitioner use of the transtheoretical model of change for breastfeeding facilitation. Clinical Excellence for Nurse Practitioners. 2005; 9:192-194.

Irwin JD, He M, Bouck LM, Tucker P, Pollett GL. Preschoolers' physical activity behaviours: Parents' perspectives. Canadian Journal of Public Health. 2005; 96:299-303.

Jenkins S, Horner SD. Barriers that influence eating behaviors in adolescents. Journal of Pediatric Nursing. 2005; 20:258-267. [PubMed: 16030505]

Kang HT, Ju YS, Park KH, Kwon YJ, Im HJ, Paek DM, et al. Study on the relationship between childhood obesity and various determinants, including socioeconomic factors, in an urban area. Journal of Preventive Medicine and Public Health. 2006; 39:371-378. [PubMed: 17076177]

Kicklighter JR, Whitley DM, Kelley SJ, Shipskie SM, Taube JL, Berry RC. Grandparents raising grandchildren: A response to a nutrition and physical activity intervention. Journal of the American Dietetic Association. 2007; 107:1210-1213. [PubMed: 17604753]

Koplan JP, Liverman CT, Kraak VI. Committee on Prevention of Obesity in Children and Youth. Preventing childhood obesity: Health in the balance: Executive summary. Journal of the American Dietetic Association. 2005; 105:131-138. [PubMed: 15635359]

Lioret S, Volatier JL, Lafay L, Touvier M, Maire B. Is food portion size a risk factor of childhood overweight? European Journal of Clinical Nutrition. 2009; 63:382-391. [PubMed: 18030311]

Mausner, JS.; Bahn, AK. Epidemiology: An introductory text. 1st ed.. Philadelphia, PA: W.B. Saunders Company; 1974.

McGarvey EL, Collie KR, Fraser G, Shufflebarger C, Lloyd B, Norman Oliver M. Using focus group results to inform preschool childhood obesity prevention programming. Ethnicity and Health. 2006; 11:265-285. [PubMed: 16774878] 
National Cancer Institute, National Institutes of Health. [Retrieved July 31, 2009] Theory at a glance: A guide for health promotion practice. 2005. from: www.cancer.gov/theory.

NC Prevention Partners. [Retrieved December 6, 2010] Starting the Conversation Series. 2010. from: http://www.ncpreventionpartners.org/dnn/services/resources/startingtheconversationseries/tabid/ 82/default.aspx.

Nemet D, Barkan S, Epstein Y, Friedland O, Kowen G, Eliakim A. Short- and long-term beneficial effects of a combined dietary-behavioral-physical activity intervention for the treatment of childhood obesity. Pediatrics. 2005; 115:e443-e449. [PubMed: 15805347]

Neumark-Sztainer D, Story M, Perry C, Casey A. Factors influencing food choices of adolescents: Findings from focus-group discussions with adolescents. Journal of the American Dietetic Association. 1999; 99:929-937. [PubMed: 10450307]

Neumark-Sztainer D, Wall M, Perry C, Story M. Correlates of fruit and vegetable intake among adolescents: Findings from Project EAT. Preventive Medicine. 2003; 37:198-208. [PubMed: 12914825]

O'Dea JA. Why do kids eat healthful food? Perceived benefits of and barriers to healthful eating and physical activity among children \& adolescents. Journal of the American Dietetic Association. 2003; 103:497-501. [PubMed: 12669014]

Ogden CL, Carroll MD, Curtin LR, Lamb MM, Flegal KM. Prevalence of high body mass index in US children and adolescents, 2007-2008. Journal of the American Medical Association. 2010; 303:242-249. [PubMed: 20071470]

Omar MA, Coleman G, Hoerr S. Healthy eating for rural low-income toddlers: Caregivers' perceptions. Journal of Community Health Nursing. 2001; 18:93-106. [PubMed: 11407183]

Paxton, AE.; Ammerman, AS.; Gizlice, Z.; Johnston, LF.; Keyserling, TC. Validation of a very brief diet assessment tool designed to guide counseling for chronic disease prevention. Abstract presented at: International Society for Behavior, Nutrition, and Physical Activity; June 2007; Oslo, Norway. 2007.

Perkins MB, Jensen PS, Jaccard J, Gollwitzer P, Oettingen G, Pappadopulos E, et al. Applying theorydriven approaches to understanding and modifying clinicians' behavior: What do we know? Psychiatric Services. 2007; 58:342-348. [PubMed: 17325107]

Perrin EM, Finkle JP, Benjamin JT. Obesity prevention and the primary care pediatrician's office. Current Opinions in Pediatrics. 2007; 19:354-361.

Powers KA, Rehrig ST, Jones DB. Financial impact of obesity and bariatric surgery. Medical Clinics of North America. 2007; 91:321-338. ix. [PubMed: 17509381]

Schwimmer JB, Burwinkle TM, Varni JW. Health-related quality of life of severely obese children and adolescents. Journal of the American Medical Association. 2003; 289:1813-1819. [PubMed: 12684360]

Stanhope, M.; Lancaster, J. Community health nursing. 4th ed.. St. Louis, MO: Mosby; 1996.

Stettler N, Signer TM, Suter PM. Electronic games and environmental factors associated with childhood obesity in Switzerland. Obesity Research. 2004; 12:896-903. [PubMed: 15229327]

Stevens AB, Coon D, Wisniewski S, Vance D, Arguelles S, Belle S, et al. Measurement of leisure time satisfaction in family caregivers. Aging and Mental Health. 2004; 8:450-459. [PubMed: 15511743]

Story M, Neumark-Sztainer D, French S. Individual and environmental influences on adolescent eating behaviors. Journal of the American Dietetic Association. 2002; 102:S40-S51. [PubMed: 11902388]

Sturm R. Childhood obesity - What we can learn from existing data on societal trends, part 1. Preventing Chronic Disease. 2005a; 2:A12. [PubMed: 15670465]

Sturm R. Childhood obesity-What we can learn from existing data on societal trends, part 2. Preventing Chronic Disease. 2005b; 2:A20. [PubMed: 15888231]

Taveras EM, Berkey CS, Rifas-Shiman SL, Ludwig DS, Rockett HR, Field AE, et al. Association of consumption of fried food away from home with body mass index and diet quality in older children and adolescents. Pediatrics. 2005; 116:e518-e524. [PubMed: 16199680]

Weir LA, Etelson D, Brand DA. Parents' perceptions of neighborhood safety and children's physical activity. Preventive Medicine. 2006; 43:212-217. [PubMed: 16712912] 
Wilfley DE, Tibbs TL, Van Buren DJ, Reach KP, Walker MS, Epstein LH. Lifestyle interventions in the treatment of childhood overweight: A meta-analytic review of randomized controlled trials. Health Psychology. 2007; 26:521-532. [PubMed: 17845100]

Williams J, Wake M, Hesketh K, Maher E, Waters E. Health-related quality of life of overweight and obese children. Journal of the American Medical Association. 2005; 293:70-76. [PubMed: 15632338]

Wofford LG. Systematic review of childhood obesity prevention. Journal of Pediatric Nursing. 2008; 23:5-19. [PubMed: 18207043] 


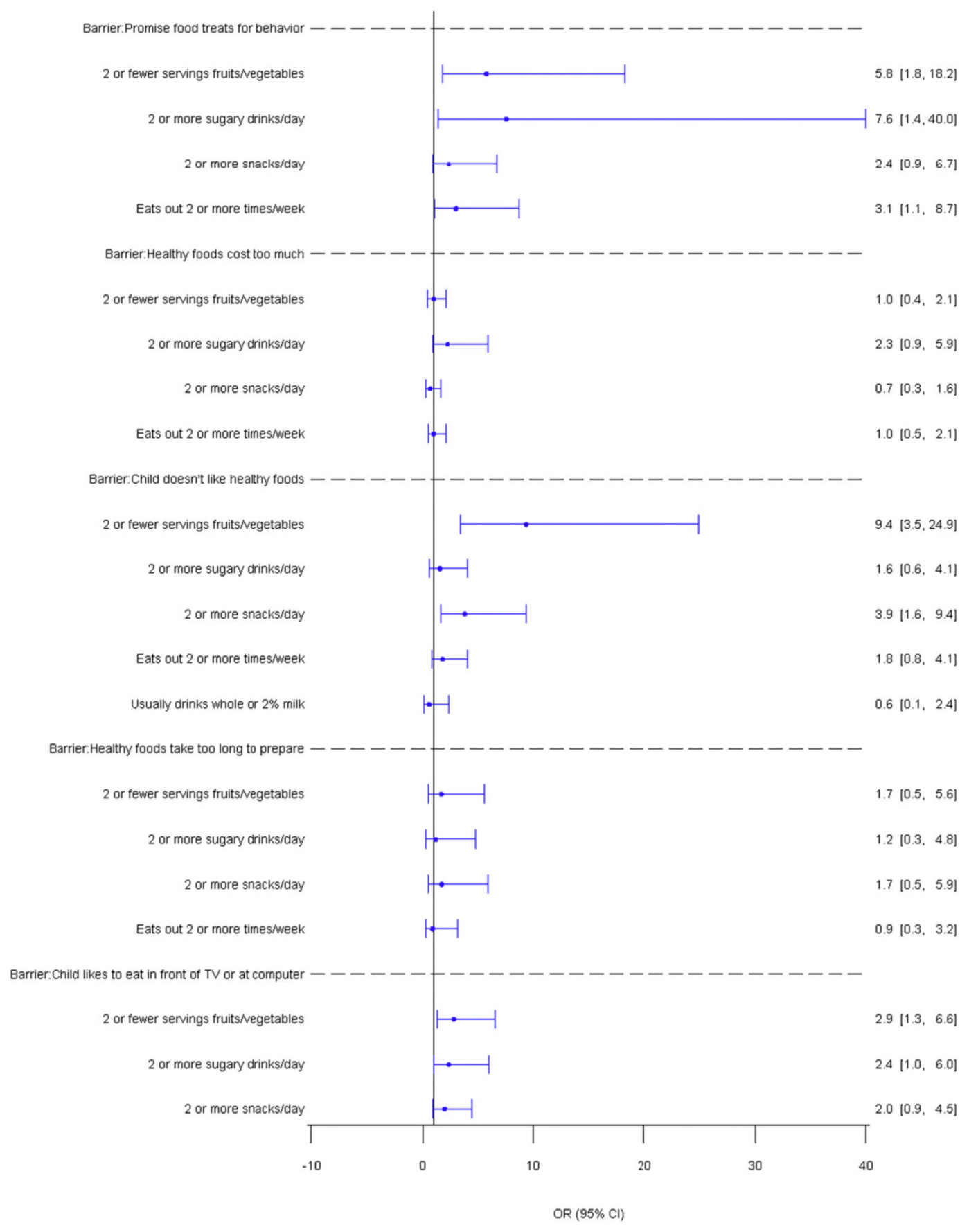

Figure 1.

Adjusted ORs of the effect of agreeing "a little" or "a lot" to diet barriers on behaviors. An OR of 1.0 (the vertical line) indicates no association between the barrier and behavior. A CI that does not cross 1.0 would indicate a statistically significant OR. 


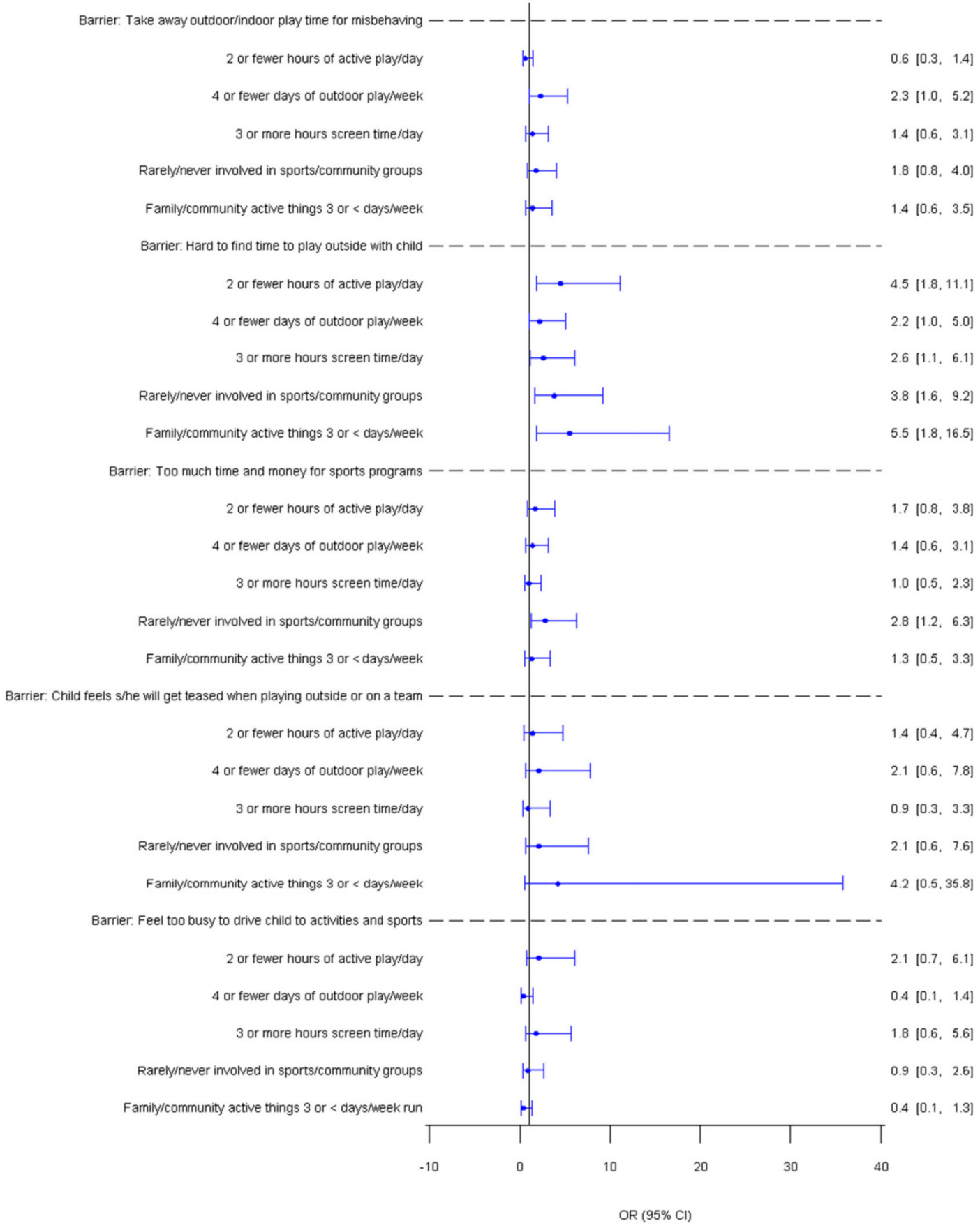

Figure 2.

Adjusted ORs of the effect of agreeing "a little" or "a lot" to physical activity barriers on physical activity behaviors. An OR of 1.0 (the vertical line) indicates no association between the barrier and behavior. A CI that does not cross 1.0 would indicate a statistically significant OR. 
Table 1

Characteristics of Children and Their Parents

\begin{tabular}{|lcc|}
\hline & $\begin{array}{c}n=115, \\
\boldsymbol{n}(\boldsymbol{\%})\end{array}$ & $\boldsymbol{M}(\mathbf{S D})$ \\
\hline Child's age (years) & & $7.5(2.8)$ \\
Child's sex, male & $58(50.4)$ & \\
Child's ethnicity & & \\
Hispanic/Latino & $9(7.8)$ & \\
Not Hispanic/Latino & $106(9.2)$ \\
Child's race & \\
American Indian/Alaskan Native & $2(1.7)$ \\
Asian & $1(0.9)$ \\
African American & $76(66.1)$ \\
White & $24(20.9)$ \\
Other & $12(10.4)$ \\
Child's insurance coverage & \\
Health choice (SCHIP) & $20(17.4)$ \\
Medicaid & $95(82.6)$ \\
Body mass index classification of child & \\
Healthy weight (5th to <85th percentile) & $58(50.4)$ \\
Overweight (85 to <95th percentile) & $17(14.8)$ \\
Obese ( $₫ 95$ th percentile) & $40(34.8)$ \\
Gender of parent, female & $106(92.2)$ \\
Parent's classification of own weight & \\
Underweight & $1(0.9)$ \\
Healthy weight & $51(44.4)$ \\
Overweight & $63(54.8)$ \\
\hline
\end{tabular}


Table 2

Distribution of Potential Barriers to Healthy Eating and Physical Activity $(n=115)$

\begin{tabular}{|c|c|c|c|c|}
\hline Variable & $\frac{\text { Disagree }}{n(\%)}$ & $\begin{array}{c}\begin{array}{c}\text { Agree } \\
\text { "A Little"/ } \\
\text { "A Lot" }\end{array} \\
n(\%)\end{array}$ & 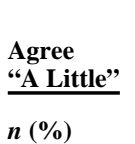 & $\begin{array}{c}\begin{array}{c}\text { Agree } \\
\text { "A Lot" }\end{array} \\
n(\%)\end{array}$ \\
\hline \multicolumn{5}{|l|}{ Healthy eating barriers } \\
\hline Promise candy or other food treats to get child to behave & $90(78.3)$ & $25(21.7)$ & $15(13.0)$ & $10(8.7)$ \\
\hline Healthy food costs too much & $67(58.3)$ & $48(41.7)$ & $28(24.3)$ & $20(17.4)$ \\
\hline Child doesn't like healthy food & $73(63.5)$ & $42(36.5)$ & $35(30.4)$ & $7(6.1)$ \\
\hline Healthy meals take too long to prepare & $102(88.7)$ & $13(11.3)$ & $10(8.7)$ & $3(2.6)$ \\
\hline Child likes to eat in front of television or at the computer & $58(50.4)$ & $57(49.5)$ & $32(27.8)$ & $25(21.7)$ \\
\hline \multicolumn{5}{|l|}{ Physical activity barriers } \\
\hline Take away outdoor/indoor play time when child misbehaves & $51(44.3)$ & $64(55.7)$ & $43(37.4)$ & $21(18.3)$ \\
\hline Hard to find time to play outside with child & $56(49.1)$ & $58(50.8)$ & $38(33.3)$ & $20(17.5)$ \\
\hline Takes too much time and money to have child involved with sports programs & $67(58.3)$ & $48(41.7)$ & $36(31.3)$ & $12(10.4)$ \\
\hline Child feels that s/he will get teased when playing outside or on a team & $100(87.0)$ & $15(13.1)$ & $8(7.0)$ & $7(6.1)$ \\
\hline Too busy to drive child to activities and sports & $97(84.3)$ & $18(15.6)$ & $12(10.4)$ & $6(5.2)$ \\
\hline
\end{tabular}

